\title{
Cancer Surgery in Elderly People - Specific Facts Concerning the Management: Review of Literature
}

\author{
Corina Elena Minciuna ${ }^{1}$, Stefan Tudor ${ }^{* 1}$ and Catalin Vasilescu ${ }^{1,2}$ \\ ${ }^{1}$ General Surgery Department, Fundeni Clinical Institute, Romania \\ ${ }^{2}$ Carol Davila" University of Medicine and Pharmacy, Romania \\ *Corresponding author: Stefan Tudor, General Surgery Department, Fundeni Clinical Institute, Romania
}

\section{ARTICLE INFO}

Received: 蔧 February 22, 2019

Published: 櫘 February 26, 2019

Citation: Minciuna C-E, Tudor S, Vasilescu C. Cancer Surgery in Elderly People - Specific Facts Concerning the Management: Review of Literature. Biomed J Sci \& Tech Res 15(2)-2019. BJSTR. MS.ID.002664.
ABSTRACT

As the life expectancy raised, the general surgeon deals with more elderly patients thus the importance of understanding the specific problems and management. The main difficulties evaluated are suboptimal treatment; ineffective assessment; comorbidities and multidrug-use; lack of education in elderly care; lack of social support; age discrimination and priorities of the patient. Health care providers must be vigilant, if they are to treat and cope with the challenges that come with elderly patients. They must see the heterogeneity of the population and be prepared to deal with them accordingly, the chronological age is not a barrier and neither our preconceived ideas.

Keywords: Elderly; Surgery; Discrimination; Suboptimal Treatment; Comorbidities; Assessment; Social Support

\section{Introduction}

We live in a world that is constantly getting older, from 2010 the percentage of older people surpassed that of children under 5 , this means on one side that the life expectancy raised and on the other hand that the general surgeon deals with an older global population (Figure 1) [1]. Many definitions of the elder where proposed, depending on country and life expectancy. In most developed countries the cut off for being an elder was set at 65, in Africa is 50 years old and United Nations considers the age of 60 years to be the threshold [2]. Incidence of neoplastic diseases increased significantly after 65 years; given the increase in life expectancy, the surgeons deals more and more with elderly oncological patients.
Over the last eight years in General Surgery Department, Fundeni Clinical Institute a constant increase in the number of patients older than 65 years was recorded (Figure 2). This has raised the interest to review the literature on how to manage the surgical elderly patient, do deal with the specific problems managing this type of patient and to find the optimal solution. After reviewing the up to date literature, the following specific facts regarding elderly management were found suboptimal treatment; ineffective assessment; comorbidities and multidrug-use; lack of education in elderly care; lack of social support; age discrimination and priorities of the patient [3-6].

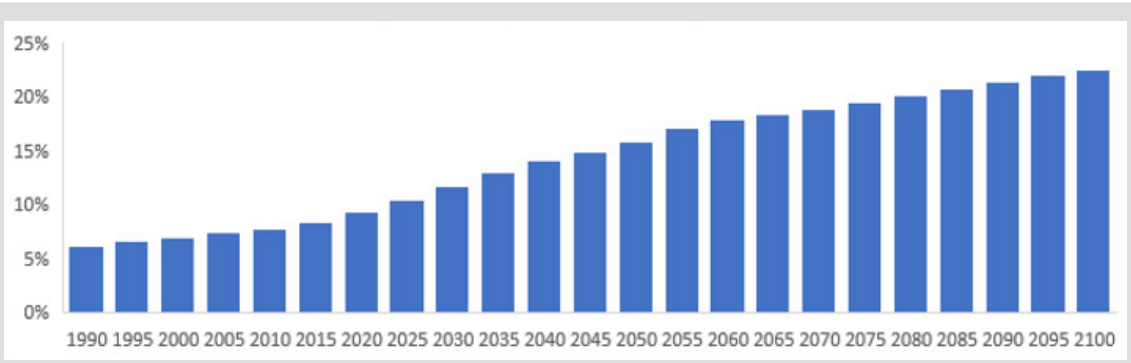

Figure 1: Percentage of 65+\% year old through 1990-2100 [1]. 


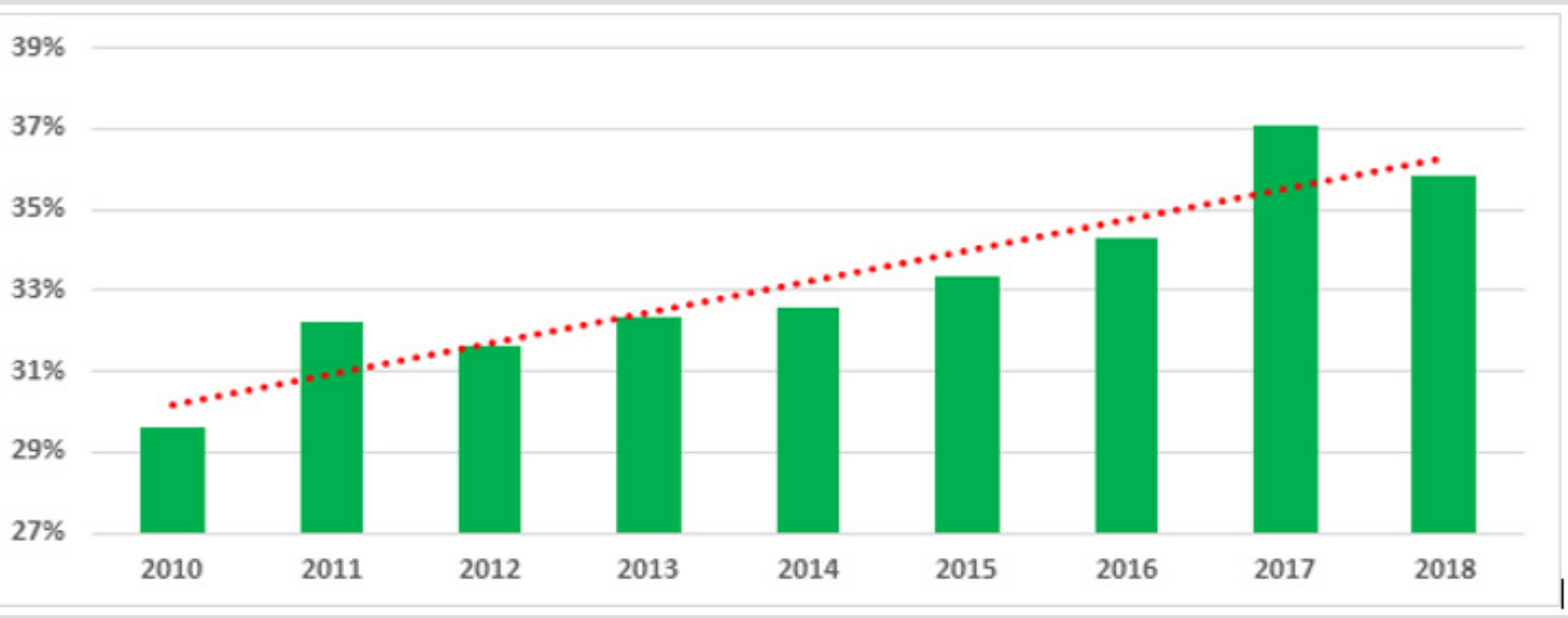

Figure 2: Percentage of elderly (>65 years) who had undergone surgery in Fundeni Clinical Institute (2010-2018).

\section{Suboptimal Treatment}

The risk for poor quality-of-care the elderly were identified in a paper published by Asch S.M., demonstrating that the quality of care declined with age [7]. NCIN analysed the percentage of patients with a record of a major resection by age and by cancer site, between 2004-2006 and concluded that there is a large decrease in the percentage of patients receiving a major resection over 50 years old. Less than $2 \%$ of patients over 80 years had a major resection for cancer. This applies for chemotherapy and radiotherapy, too [8]. There is a lack in clinical trials designed especially for the elderly and as a result, the optimal therapy is not clearly established. Elderly people are unrepresented in surgical trials, the available data are from retrospective studies and there are no randomized studies specifically design for the elderly therefore there is a need for clinical trials to better analyse the risk-benefit ratio for the older people [9]. Multiple studies are emerging in treating cancer in elderly. In 2008, NCCN Task Force Report on Brest cancer in older women gathered 18 experts in breast cancer to establish and develop recommendations [10].

One of the constraints was the heterogeneous population. Controversies raised the lack of knowledge in tumor biology in older patients and implementation of specific interventions, making them the areas requiring future studies. Sakurai K [11] evaluated the outcome of surgical treatment for gastric carcinoma in the elderly concluded that there is no significant difference of postoperative complication rate between the control and the elderly group. Since $60 \%$ of colorectal patients are older than 70 years and less likely to receive guideline-recommended therapies, the need of comprehensive treatment plan and of a multidisciplinary team to better evaluate these patients was identified by Itatani $Y$ [12]. NCCN released an Older Adult Oncology Guide to help the clinician to better approach the decision-making in older-adults [13]. Surgical risk should not have as primary consideration the age, should be focused on assessing the physiological status and should keep in mind that emergency surgery increases the risk of complications. They identified as a risk factor the impaired cognitive status for postoperative complications. Postoperative risk for delirium increases with age and in the same time is a risk factor for functional and cognitive decline, which must be addressed prior to the surgery instating preventive measures.

\section{Ineffective Assessment}

The heterogeneity of the elderly population is a barrier to establish clear guidelines and to design clinical trials. The chronological age alone is not enough to assess the functional status and nor is an evaluation of it. The use of comprehensive geriatric assessments in order to recommend appropriate treatment needs to be used, even if it's time-consuming. It is mandatory to be implemented, especially in oncological evaluation. This assessment creates a better picture of nutritional status, cognition, coping mechanisms, quality of life and other health problems. "One size does not fit all" applies better in elderly people management more than anywhere. Ruiz M [14] highlights the need of comprehensive geriatrics assessment and other evaluation tools.

A dedicated geriatric surgery service was proposed by Tan K et al. [15] to better assess elderly colorectal surgery patients, stating that were able to achieve sustained superior outcomes compared with standard management. Another possible solution can be to include in the Oncological Treatment Board a geriatrician, who has a better understanding of the problem. American College of Surgeons and American Geriatrics Society acknowledged this problem and released a best practices guideline for optimal perioperative management of the geriatric patient $[16,17]$. "Time up and go" is a screening tool that predicts 30-day morbidity in onco-geriatric surgical patients. Huisman M [18] conducted a multicenter cohort study identifying twice as many onco-geriatric 
patients at risk of post-operative complications, who might benefit from pre-operative interventions, using TUG rather than using ASA.

\section{Comorbidities and Multidrug Use}

Elderly patients frequently have more comorbidities than the younger patients, that often is a therapeutically limiting problem in older cancer patients. The comorbidity burden has no standard measure. A frequently mistake is to assume that comorbidity and functional status are dependent. Extermann M [19] acknowledged that comorbidity is independent from the functional status and need to be assessed separately in older cancer patients. There is a constant need of identification and in advanced management of comorbidities, identification of subclinical organ involvement which may decompensate under the intended treatment and evaluation of the risk of drug interactions, planning the treatment and consider other treatment options if drug interactions cannot be controlled. Lees J. and Chan A. recognized the implications of polypharmacy and the upgrowing problem that will become [20].

\section{Lack of Education un Elderly Care}

Surgeons and specialists rarely receive training in geriatrics, but the fact that they serve an increasingly older population makes it mandatory. From 1994, in United States of America a project has begun under the supervision of American Geriatric Society to improve the knowledge in geriatrics education that surgical residents receive: The Geriatric Education for Specialty Residents [21]. Steps were made to improve and implement the curricula $[22,23]$. Many efforts were made to develop a list of explicit competencies in elderly care that could be used by the certifying boards to assist them [24].

\section{Lack of Social Support}

Better social support improves the compliance to the treatment. Elderly people don't have the necessary home support, the means to reach the hospital and additionally, they take care of dependent spouses and other family members. They lack the social support because at that age many of their friends and family have already passed away. Tralongo P [25] bring to the table a new way to improve the health care in oncology, cancer patient-centered home care. This model can also be used for the period of recovery after surgery, bringing down the costs associated to longer hospitalization. The model of patient-centred care is based on their needs rather than prognosis.

\section{Age Discrimination}

National Cancer Equality Initiative states that elderly receive less active and intensive treatment than younger patients, even though they can tolerate similar treatment regimens and they are more likely to be admitted as emergencies [26]. The professional attitudes can be a barrier that may impede to get access to a full range of treatments options and the decrease in cancer mortality in elderly has been less marked than for the younger. Comprehensive information needs to be delivered in an appropriate manner that they can understand and in the same time acknowledge the difficulties accessing appropriate cancer services (socio-economic deprivation, gender, sexuality, race and disability). Age should not be a barrier to treatment; they should receive the same level of treatment. A frequent mistake is to assume their life expectancy and to consider that the treatment will not prolong their life, more then they will have lived with the natural evolution of the disease. This is how the term of "age-ism" appeared. To counteract this phenomenon NHS practice guide: achieving age equality in health and social care was created, following the problems raised by the Cancer Reform Strategy [27].

\section{Priorities of the Patient}

The optimal treatment plan for the elderly must clearly establish the goals of the treatment (cancer-specific treatment, symptomatic treatment, supportive treatment, end-of-life care) [28]. Most old patients will know exactly their priorities, in addition to simply prolong their lives. Their top concerns consist in avoiding suffering, being mentally aware, not being a burden to others, strengthening relationships and achieving a sense of a complete life [29].

\section{Final Consideration}

More and more elderly patients with cancer will address the general surgery departments. Age should not be a barrier to treatment. Optimal approach will take into consideration challenges that come with elderly people and their functional status. There is a need of clinical trials design especially for elderly including as endpoints life expectancy, the effect of treatment on quality of life and the cost of treating older cancer patients.

\section{References}

1. (2017) United Nations Department of Economic and Social Affairs Population Division. World Population Prospects: The 2017 Revision, custom data acquired via website.

2. (2019) Proposed working definition of an older person in Africa for the MDS Project.

3. Swaminathan V, Audisio R (2012) Cancer in older patients: an analysis of elderly oncology. Ecancermedicalscience 6: 243.

4. Johnston ME, Sussman JJ, Patel SH (2019) Surgical Oncology and Geriatric Patients. Clin Geriatr Med 35(1): 53-63.

5. Audisio RA, Zbar AP, Jaklitsch MT (2007) Surgical management of oncogeriatric patients. J Clin Oncol 25(14):1924-1929.

6. Devane C (2019) The age-old excuse: the under treatment of older cancer patients. Macmillan cancer support.

7. Asch SM, Kerr EA, Keesey J, Adams JL, Setodji CM, et al. (2006) Who Is at Greatest Risk for Receiving Poor-Quality Health Care? New England Journal of Medicine 354: 1147-1156.

8. (2007) National Cancer Intelligence Network NHS treated cancer patients receiving major surgical resections - NCIN Data Briefing.

9. Termuhlen PM, Kemeny MM (2002) Surgery in the older patient. Oncology (Williston Park) 16(2): 183-189.

10. Carlson RW, Moench S, Hurria A, Balducci L, Burstein HJ, et al. (2008) NCCN Task Force Report: breast cancer in the older woman. J Natl Compr Canc Netw 6 Suppl 4: S1-25. 
11. Sakurai K, Muguruma K, Nagahara H, Kimura K, Toyokawa T, et al. (2015) The outcome of surgical treatment for elderly patients with gastric carcinoma. J Surg Oncol 111(7): 848-854.

12. Itatani Y, Kawada K, Sakai Y (2018) Treatment of Elderly Patients with Colorectal Cancer. Biomed Res Int 2018: 2176056.

13. VanderWalde N, Jagsi R, Dotan E, Baumgartner J, Browner IS, et al. (2016) NCCN Guidelines Insights: Older Adult Oncology, Version 2.2016. J Natl Compr Canc Netw 14(11): 1357-1370.

14. Ruiz M, Reske T, Cefalu C, Estrada J (2013) Management of elderly and frail elderly cancer patients: the importance of comprehensive geriatrics assessment and the need for guidelines. Am J Med Sci 346(1): 66-69.

15. Tan HJ, Saliba D, Kwan L, Moore AA, Litwin MS (2016) Burden of Geriatric Events Among Older Adults Undergoing Major Cancer Surgery. J Clin Oncol 34(11): 1231-1238.

16. Mohanty S, Rosenthal RA, Russell MM, Neuman MD, Ko CY, et al. (2016) Optimal Perioperative Management of the Geriatric Patient: A Best Practices Guideline from the American College of Surgeons NSQIP and the American Geriatrics Society. J Am Coll Surg 222(5): 930-947.

17. Tan KY, Tan P, Tan L (2011) A collaborative transdisciplinary "geriatric surgery service" ensures consistent successful outcomes in elderly colorectal surgery patients. World J Surg 35(7): 1608-1614.

18. Huisman MG, van Leeuwen BL, Ugolini G, Montroni I, Spiliotis J, et al. (2014) "Timed Up \& Go": a screening tool for predicting 30-day morbidity in onco-geriatric surgical patients? A multicenter cohort study. PLoS One 9(1): e86863.

19. Extermann M, Overcash J, Lyman GH, Parr J, Balducci L (1998) Comorbidity and functional status are independent in older cancer patients. J Clin Oncol 16(4): 1582-1587.

ISSN: 2574-1241

DOI: 10.26717/BJSTR.2019.15.002664

Stefan Tudor. Biomed J Sci \& Tech Res

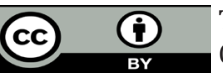

This work is licensed under Creative Commons Attribution 4.0 License

Submission Link: https://biomedres.us/submit-manuscript.php
20. Lees J, Chan A (2011) Polypharmacy in elderly patients with cancer: clinical implications and management. Lancet Oncol. 2011 Dec;12(13): 1249-1257.

21. Potter JF, Burton JR, Drach GW, Eisner J, Lundebjerg NE, et al. (2005) Geriatrics for residents in the surgical and medical specialties: implementation of curricula and training experiences. J Am Geriatr Soc 53(3): 511-515.

22. Webb TP, Duthie E Jr (2008) Geriatrics for surgeons: infusing life into an aging subject. J Surg Educ 65(2): 91-94.

23. Barbas AS, Haney JC, Henry BV, Heflin MT, Lagoo SA (2014) Development and implementation of a formalized geriatric surgery curriculum for general surgery residents. Gerontol Geriatr Educ 35(4): 380-94.

24. Bell RH Jr, Drach GW, Rosenthal RA (2011) Proposed competencies in geriatric patient care for use in assessment for initial and continued board certification of surgical specialists. J Am Coll Surg 213(5):683690.

25. Tralongo P, Ferrau F, Borsellino N, Verderame F, Caruso M, et al. (2011) Cancer patient-centered home care: a new model for health care in oncology. Ther Clin Risk Manag 7: 387-392.

26. (2019) National Cancer Equality Initiative.

27. Ros Levenson, Nikki Joule, Mercy Jeyasingham, Charlotte Potter (2010) NHS. Achieving age equality in health and social care NHS practice guide.

28. Audisio RA, Bozzetti F, Gennari R, Jaklitsch MT, Koperna T, et al. (2004) The surgical management of elderly cancer patients; recommendations of the SIOG surgical task force. Eur J Cancer 40(7): 926-938.

29. Gawande A (2014) Being Mortal: illness, medicine and what matters in the end. London: Profile Books in Association with Wellcome Collection.

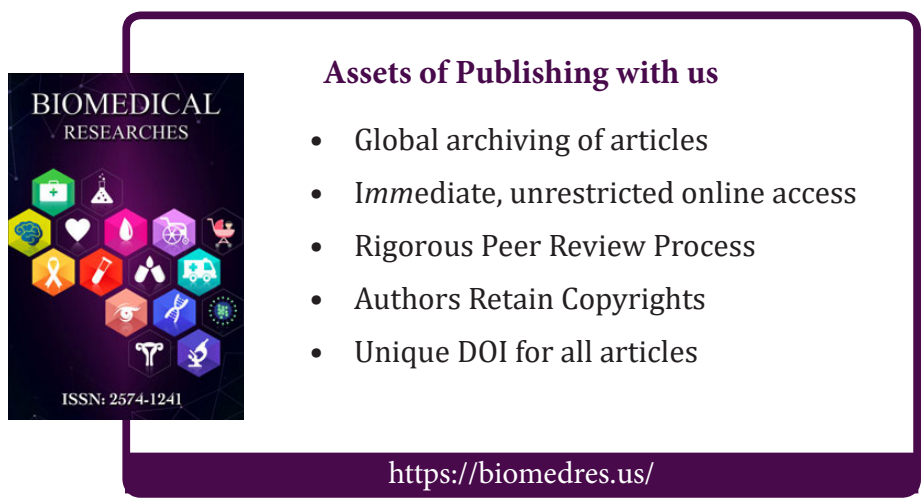

